\title{
Intraperitoneal ketorolac for post-cholecystectomy pain: a double-blind randomized-controlled trial
}

\section{Administration intra-péritonéale de kétorolac pour le traitement de la douleur post-cholécystectomie: une étude randomisée contrôlée à double insu}

\author{
John Murdoch, MBChB • Gillian Ramsey, MD • Andrew G. Day, MSc • Michael McMullen, MD • \\ Elizabeth Orr, RN $\cdot$ Rachel Phelan, MSc $\cdot$ Diederick Jalink, MD
}

Received: 28 April 2015/Revised: 11 January 2016/Accepted: 4 February 2016/Published online: 10 February 2016

(C) Canadian Anesthesiologists' Society 2016

\begin{abstract}
Purpose Ketorolac is a parenterally active nonsteroidal anti-inflammatory drug with localized anti-inflammatory properties. We examine the postoperative analgesic efficacy of locally administered intraperitoneal (IP) ketorolac compared with intravenous (IV) ketorolac during laparoscopic cholecystectomy.

Methods With institutional ethics approval, 120 patients undergoing elective laparoscopic cholecystectomy were randomized to receive intraoperative 1) IP ketorolac $30 \mathrm{mg}$ + intravenous saline (IP group), 2) intraperitoneal saline + IV ketorolac $30 \mathrm{mg}$ (IV group), or 3) intraperitoneal saline + intravenous saline (Control group) under standardized anesthesia. The primary and secondary outcomes were postoperative fentanyl requirements in the postanesthesia care unit and the time to first analgesic request, respectively. Other outcomes examined included abdominal pain (at rest and with coughing), shoulder pain,
\end{abstract}

J. Murdoch, MBChB $(\square) \cdot$ M. McMullen, MD · E. Orr, RN R. Phelan, MSc

Department of Anesthesiology \& Perioperative Medicine,

Victory 2, Kingston General Hospital, Queen's University, 76

Stuart Street, Kingston, ON, Canada K7L 2V7

e-mail: murdochj@kgh.kari.net

G. Ramsey, MD

Department of Anesthesiology, Children's Hospital of Eastern Ontario, University of Ottawa, Ottawa, ON, Canada

\section{A. G. Day, MSc}

Kingston General Hospital Research Institute, Kingston General Hospital, Kingston, ON, Canada

D. Jalink, MD

Department of Surgery, Kingston General Hospital, Queen's University, Kingston, ON, Canada nausea, vomiting, and any other postoperative complications.

Results On average, patients receiving IP ketorolac required less (mean difference, $29 \mu \mathrm{g} ; 95 \%$ confidence interval [CI], 2 to 56; $P=0.04$ ) fentanyl than patients in the Control group but a similar (mean difference, $16 \mu \mathrm{g}$; 95\% CI, 12 to 43; $P=0.27$ ) amount compared to patients in the IV group. There was an increase in the median (interquartile range $[I Q R]$ ) time to first request in the IP group (43[30-52] min) compared with the Control group (35 [27-49]min; $P=0.04$ ) but no difference between the IP group compared with the IV group (47 [40-75] min; $P=$ 0.22 ). Shoulder pain and resting pain were reduced with IP and IV ketorolac compared with Control, but there was no difference between the IP and IV groups. No differences were observed in any other outcomes, side effects, or complications attributable to opioids or ketorolac at any time points.

Conclusion This study did not demonstrate any advantage for the off-label topical intraperitoneal administration of ketorolac in this surgical population. Intraperitoneal and IV ketorolac showed comparable analgesic efficacy following laparoscopic cholecystectomy.

\footnotetext{
Résumé

Objectif Le kétorolac est un agent anti-inflammatoire non stéroüdien à action parentérale et possédant des propriétés anti-inflammatoires localisées. Nous avons examiné l'efficacité analgésique postopératoire d'une administration intra-péritonéale (IP) locale de kétorolac par rapport à une administration intraveineuse (IV) pendant une cholécystectomie par laparoscopie.

Méthode Après avoir obtenu le consentement du Comité d'éthique de notre institution, 120 patients subissant une
} 
cholécystectomie par laparoscopie non urgente ont été randomisés à recevoir en peropératoire l'un des trois traitements suivants: 1) $30 \mathrm{mg}$ de kétorolac IP + une solution saline intraveineuse ip (groupe IP); 2) une solution saline intra-péritonéale $+30 \mathrm{mg}$ de kétorolac IV iv (groupe IV); ou 3) une solution saline intra-péritonéale + une solution saline intraveineuse (groupe témoin) sous anesthésie standardisée. Les critères d'évaluation primaire et secondaire étaient les besoins postopératoires en fentanyl en salle de réveil et le délai jusqu'à la première demande d'analgésie, respectivement. Les autres critères d'évaluation ont examiné la douleur abdominale (au repos et en toussant), la douleur aux épaules, les nausées, les vomissements et toutes les autres complications postopératoires.

Résultats En moyenne, les patients ayant reçu $d u$ kétorolac IP ont eu besoin de moins de fentanyl (différence moyenne, $29 \mu \mathrm{g}$; intervalle de confiance [IC] $95 \%, 2$ à 56; $P=0,04)$ que les patients du groupe témoin, mais une quantité semblable (différence moyenne, $16 \mu \mathrm{g}$; IC $95 \%, 12$ à 43; $P=0$,27) à ceux du groupe IV. Nous avons observé une augmentation du temps moyen (écart interquartile [ÉIQ]) jusqu'à la première demande dans le groupe IP (43[30-52] min) par rapport au groupe témoin (35 [27-49] min; $P=0,04)$, mais aucune différence entre le groupe IP et le groupe IV (47 [40-75] min; P =0,22). La douleur aux épaules et la douleur au repos étaient moindres dans les groupes kétorolac IP et IV par rapport au groupe témoin, mais aucune différence n'a été observée entre les groupes IP et IV. Aucune différence n'a été observée en ce qui touchait à nos autres critères, aux effets secondaires ou aux complications attribuables aux opiö̈des ou au kétorolac et ce, à n'importe quel moment de notre analyse.

Conclusion Cette étude n'a pas démontré d'avantage à une administration intra-péritonéale topique non conforme de kétorolac dans cette population chirurgicale. Le kétorolac en administration intra-péritonéale et IV a montré une efficacité analgésique comparable après une cholécystectomie par laparoscopie.

Laparoscopic cholecystectomy is often performed on an outpatient basis, but the procedure can cause moderate to severe postoperative pain which delays or prevents sameday discharge in over $16 \%$ of patients. ${ }^{1}$ This pain has been characterized as incisional, visceral/abdominal, and/or in the shoulder ${ }^{1}$ and reaches maximal intensity during the first four to eight hours following surgery. ${ }^{1,2}$ A putative mechanism for the visceral component is the release of inflammatory mediators, such as prostaglandins, from the distension of the peritoneum during creation of the pneumoperitoneum. ${ }^{3}$ Although the pain can be managed with opioid analgesics, the opioid-associated side effects may delay timely discharge. As a result, alternative multimodal pain management strategies have been explored to reduce or eliminate opioid requirements ${ }^{1}$ while maintaining effective analgesia. ${ }^{2-5}$ Such regimens often include nonsteroidal anti-inflammatory drugs (NSAIDs), which have shown localized anti-inflammatory and analgesic properties through the inhibition of prostaglandin synthesis directly at the site of tissue trauma $^{6}$ via different degrees of cyclooxygenase 1 and 2 inhibition. ${ }^{7}$ For this surgical population, NSAIDS have been shown to reduce postoperative opiate requirements by up to $30 \%$, with an associated reduction in recovery times and a decrease in the incidence of vomiting. ${ }^{4}$

Given their action at the site of injury, topical administration of NSAIDs may have some putative benefits in targeting maximal concentration of the drug at the source of the pain while potentially reducing systemic side effects such as gastric irritation, renal impairment, ${ }^{8}$ and increased risk of bleeding. ${ }^{6,7}$ Ketorolac tromethamine is a parenterally active and potent NSAID with an analgesic efficacy comparable to approximately $12 \mathrm{mg}$ of morphine. ${ }^{9}$ Its topical administration has been shown to be as effective as systemic administration in mastectomies ${ }^{10}$ and more effective when infiltrated locally in inguinal hernia repair. ${ }^{11}$

The objective of this investigation was to determine whether patients undergoing laparoscopic cholecystectomy with $30 \mathrm{mg}$ intraoperatively administered intraperitoneal (IP) ketorolac experience superior postoperative pain relief compared with those who receive $30 \mathrm{mg}$ intravenous (IV) ketorolac and those who receive $0.9 \%$ saline (Control), as indicated by postoperative opioid requirements while in the postanesthesia care unit (PACU) and the time to first analgesic request.

\section{Methods}

Approval for this investigation was obtained from the Queen's University Faculty of Health Sciences and Affiliated Teaching Hospitals Research Ethics Board (ANAE-101-04, Aug. 3, 2004) and from Health Canada's Therapeutic Products Directorate (NOL\# 091936). This study was not registered on a clinical trials registry as it was not a requirement during this time frame. During the recruitment stage, 486 patients undergoing elective laparoscopic cholecystectomy as day surgery at an academic ambulatory care centre were assessed for eligibility. Patients were excluded if they had a known 
sensitivity to NSAIDs, a history of asthma, chronic obstructive pulmonary disease, peptic ulcer disease or renal impairment, a body mass index $>38$, a chronic pain syndrome, regular use of opiate pain medications, or a history of drug abuse.

All patients were premedicated with acetaminophen 975 mg po one hour prior to surgery, and they received a standardized general anesthetic. Intravenous induction was achieved with propofol, fentanyl (up to $2 \mu \mathrm{g} \cdot \mathrm{kg}^{-1}$ ), rocuronium $0.6 \mathrm{mg} \cdot \mathrm{kg}^{-1}$ or succinylcholine $1 \mathrm{mg} \cdot \mathrm{kg}^{-1}$, and ondansetron $4 \mathrm{mg}$. All patients underwent endotracheal intubation and mechanical ventilation to maintain normocarbia. Anesthesia was maintained with $70 \%$ nitrous oxide in oxygen and desflurane, intravenous fentanyl boluses (up to $3 \mu \mathrm{g} \cdot \mathrm{kg}^{-1}$ ), rocuronium to maintain muscle relaxation, and intravenous fluids administered as Ringer's lactate (minimum of 20 $\mathrm{mL} \cdot \mathrm{kg}^{-1}$ ) at the discretion of the attending anesthesiologist. All incision sites were infiltrated with $0.25 \%$ bupivacaine, and $\mathrm{CO}_{2}$ insufflation pressure was limited to a maximum of $15 \mathrm{mmHg}$.

Patients were randomly assigned preoperatively to one of three intraoperative treatment groups by means of a computer-generated randomization sequence. The randomization table was generated in blocks of six to obtain groups that were nearly equal in size. The pharmacy prepared and distributed the medication packages (identical in appearance with coded bags and syringes) according to the randomization sequence. The IP group $(n=41)$ received intraperitoneal ketorolac $(30 \mathrm{mg}$ in $250 \mathrm{~mL}$ normal saline) and intravenous normal saline $1 \mathrm{~mL}$. The IV group $(n=39)$ received intraperitoneal normal saline 250 $\mathrm{mL}$ and intravenous ketorolac (30 $\mathrm{mg}$ in $1 \mathrm{~mL}$ ). The Control group $(n=40)$ received intraperitoneal normal saline $250 \mathrm{~mL}$ and intravenous normal saline $1 \mathrm{~mL}$. After dissection of the gall bladder and achieving hemostasis, the surgeon administered the intraperitoneal injection through the suction port with patients in a supine level position. One-half of the injectate $(125 \mathrm{~mL})$ was directed at the gall bladder bed, and the remaining volume $(125 \mathrm{~mL})$ was directed under the right hemidiaphragm. The attending anesthesiologist delivered the intravenous injections at the same time. Completion of intraperitoneal/intravenous administration was considered time zero.

In the PACU, pain was evaluated using a $100-\mathrm{mm}$ visual analogue scale (VAS) ranging from $0=$ no pain to $100=$ maximum pain. A blinded observer recorded the scale scores at $30 \mathrm{~min}, 60 \mathrm{~min}, 120 \mathrm{~min}$, and prior to discharge with the patient both at rest and coughing. The occurrence of shoulder tip pain was also recorded. At the patient's request, nursing staff administered rescue analgesia as fentanyl 25- $\mu \mathrm{g}$ boluses every three minutes up to a maximum of $250 \mu \mathrm{g}$, according to standard institutional practice. Time to first request for analgesia, total fentanyl use, incidence of nausea and/or vomiting, and need for antiemetic treatment were recorded.

Patients were discharged home with oral analgesia consisting of acetaminophen $975 \mathrm{mg}$ every six hours and oxycodone 5-10 mg every four hours as required. They were instructed to take the acetaminophen for mild pain and the oxycodone for moderate to severe pain. Patients were contacted by telephone at $24 \mathrm{hr}$ and asked to complete the following information on a mail-in datasheet: VAS pain score at $24 \mathrm{hr}$, worst pain over the past $24 \mathrm{hr}$, incidence and severity of nausea and vomiting, and return to activities of daily living score (on a verbal rating scale of 1-10, with $1=$ no activity and $10=$ back to normal activity). Patients were also asked about any side effects. Patients were again contacted by telephone two weeks postoperatively and any adverse events were recorded.

For the primary and secondary outcomes, we used a hierarchical hypothesis testing strategy to match the study design to the objectives while controlling the overall type I error rate at alpha $=0.05$. Specifically, we compared the IP group with Control at a two-sided alpha $=0.05$. If, and only if, this comparison was significant, we then compared the IP group with the IV group at a two-sided alpha $=0.05$. Safety and tertiary outcomes were compared between all three groups without adjustment for multiplicity.

The primary outcome was the amount of fentanyl required in the PACU. Our sample size calculation was based on the work by Elhakim et al. ${ }^{5}$ We converted their nalbuphine rescue doses to fentanyl equivalents, assuming fentanyl to be 100 times more potent. From this work, we estimated the mean (SD) amount of fentanyl required in the PACU to be 220 (80) $\mu \mathrm{g}$ in the saline group, 180 (80) $\mu \mathrm{g}$ in the IV group, and 140 (80) $\mu \mathrm{g}$ in the IP group. We considered a $33 \%$ reduction in opioid consumption minimally clinically important. Assuming a within-group standard deviation of $80 \mu \mathrm{g}$ and assuming that the IP arm differs from both the IV and Control arms by at least $70 \mu \mathrm{g}$, then using the hierarchical testing strategy described above, we would achieve $95 \%$ power to compare IP vs Control and $90 \%$ power to compare IP vs IV, respectively. The sample size was increased to 40 patients per arm to allow for missing data. The primary outcome and all continuous outcomes were described by group using means and standard deviations. Between-group differences with $95 \%$ confidence intervals and $P$ values were estimated by oneway analysis of variance. $P$ values were not adjusted due to the hierarchical testing approach.

The secondary outcome was the time to first analgesic request, defined as the time from the completion of the intraperitoneal/intravenous injection to the time for first patient request for analgesia in the PACU. Patients who did not request analgesia were censored at $180 \mathrm{~min}$, which was 
after the last request for analgesia. We used a KaplanMeier curve to depict the time to first analgesic and tested between-group differences by the log-rank test. Presence of shoulder pain, nausea, and vomiting were tested between groups using the Fisher's exact test. All analysis was performed using $\mathrm{SAS}^{\circledR}$ version 9.2 (SAS Institute Inc., Cary, NC, USA).

\section{Results}

Of the 486 patients assessed, 366 were excluded because they met exclusion criteria $(n=239)$, refused to participate $(n=34)$, were enrolled in other studies $(n=91)$, or their cases involved anticipated surgical complications resulting in withdrawal prior to randomization $(n=2)$. The final study included 120 patients (aged 18-69 yr and American Society of Anesthesiologists physical status I-III) undergoing elective laparoscopic cholecystectomy as day surgery. All participants provided written informed consent prior to enrolment and underwent surgery during January 2005 to March 2008. Overall, 88\% of the patients were female, and the average (range) age and body mass index were 43.3 (18-69) $\mathrm{yr}$ and $28.3 \quad(19-38) \mathrm{kg} \cdot \mathrm{m}^{-2}$, respectively. Characteristics of the study patients are summarized by group in Table 1 .

The data of 120 patients $(I P=41, I V=39$, Control $=40$ ) were analyzed. On the day of surgery, nine patients (IP $=2$, $\mathrm{IV}=4$, Control $=3$ ) were unable to complete their VAS pain scores due to factors such as drowsiness or nausea. Fifteen patients were not available for the 24-hr follow-up $(\mathrm{IP}=3, \mathrm{IV}=6$, and Control $=6$ ), and 13 patients were lost for the two-week follow-up (IP $=3, \mathrm{IV}=4$, and Control = 6) (Fig. 1).

In the PACU, the mean (SD) fentanyl required in the three groups was: IP, 83 (65) $\mu \mathrm{g}$; IV, 67 (54) $\mu \mathrm{g}$; and
Control, 112 (64) $\mu$ g. In the IP group, fentanyl use was lower (mean difference, $29 \mu \mathrm{g} ; 95 \%$ confidence interval [CI], 2 to $56 ; P=0.04)$ than in the Control group but similar to the IV group (mean difference, $16 \mu \mathrm{g}$; 95\% CI, 12 to $43 ; P=0.27$ ).

The median (interquartile range [IQR]) minutes to first analgesic request for the three groups were: IP, 43 [30-52] min; IV, 47 (40-75) min; and Control, 35 (27-49) min. These are graphically represented using a Kaplan-Meier curve in Fig. 2. The time to first analgesic request was significantly longer in the IP arm than in the Control arm $(P$ $=0.04$ ) but insignificantly shorter in the IP arm than in the IV $\operatorname{arm}(P=0.22)$.

The incidence of shoulder pain was significantly reduced in the IP (7\%) and IV (10\%) groups compared with the Control group (30\%) $(P=0.02)$ (Table 2). At 30, 60, and $120 \mathrm{~min}$, the VAS pain scores at rest were similar in the IP and IV groups, but both groups had significantly reduced pain scores compared with the Control group (Fig. 3A). With regard to the VAS pain scores with coughing, there were no significant differences observed between any of the groups at any of the time points examined (Fig. 3B).

There were no significant differences observed for any of the groups with respect to nausea, vomiting, antiemetic use in the PACU (Table 2), or requirement for hospital admission (Fig. 1). Also, at the 24-hr follow-up, there were no significant differences between any of the groups with regard to use of acetaminophen or oxycodone, nausea, or vomiting (Table 3). No significant differences were observed in terms of side effects or complications attributable to ketorolac.

\section{Discussion}

Both intraperitoneal and intravenous ketorolac showed comparable efficacy in managing immediate postoperative

Table 1 Summary of patient and surgical characteristics

\begin{tabular}{llll}
\hline & $\begin{array}{l}\text { IP } \\
(n=41)\end{array}$ & $\begin{array}{l}\text { IV } \\
(n=39)\end{array}$ & $\begin{array}{l}\mathrm{C} \\
(n=40)\end{array}$ \\
\hline Age $(\mathrm{yr})$ & $42(13)$ & $44(11)$ & $45(12)$ \\
Sex $(\mathrm{F}: \mathrm{M})$ & $38: 3$ & $33: 6$ & $34: 6$ \\
Height $(\mathrm{m})$ & $1.66(0.07)$ & $1.67(0.10)$ & $1.65(0.08)$ \\
Weight $(\mathrm{kg})$ & $75.2(12.4)$ & $80.4(18.5)$ & $79.0(12.4)$ \\
BMI $\left(\mathrm{kg} \cdot \mathrm{m}^{-2}\right)$ & $27(4)$ & $29(5)$ & $29(4)$ \\
Intraoperative fentanyl $(\mu \mathrm{g})$ & $212(67)$ & $196(58)$ & $199(65)$ \\
Time from study drug administration to PACU $(\mathrm{min})$ & $23[20-27]$ & $25[20-30]$ & $23.5[20-30]$ \\
Time in PACU (min) & $160[140-215]$ & $155[120-202]$ & $13,25,1$ \\
ASA score (I, II, III) & $13,28,0$ & $170[130-210]$ \\
\hline
\end{tabular}

Age, body mass index (BMI), height, weight, and intraoperative fentanyl are reported as mean (SD). Time is reported as median [interquartile range]. American Society of Anesthesiologists (ASA) score is reported as $n$. IP = intraperitoneal; IV $=$ intravenous; $\mathrm{C}=$ control; PACU $=$ postanesthesia care unit 


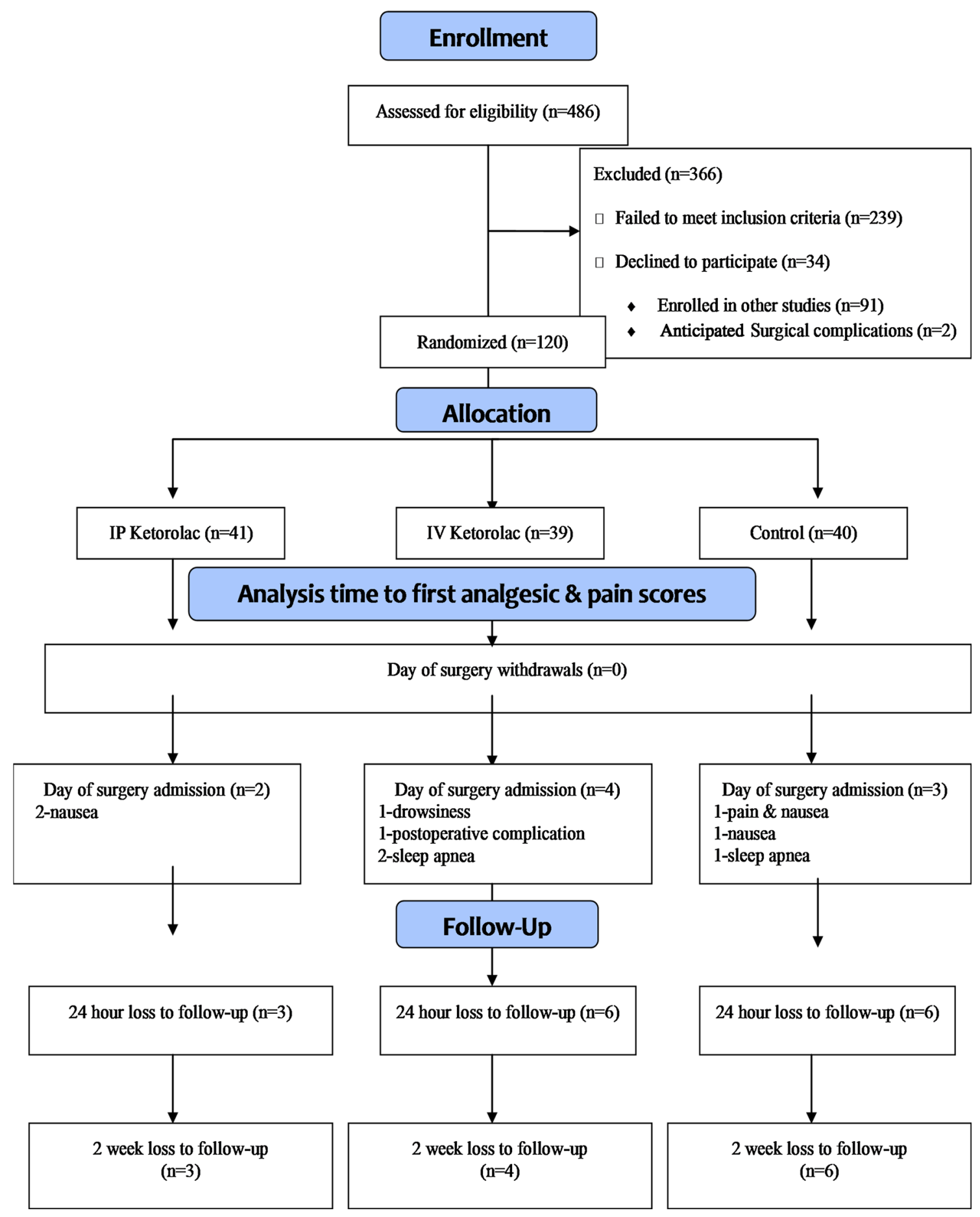

Fig. 1 CONSORT 2010 flow diagram

pain in patients undergoing laparoscopic cholecystectomy. Despite statistically significant reductions in opioid usage with ketorolac compared with the Control group, there were no differences detected in opioid side effects. Nevertheless, it should be emphasized that this study was not powered to detect differences in adverse events. Furthermore, the $25-\mu \mathrm{g}$ difference may not be clinically relevant despite statistical significance. Although our results appear to reaffirm some value in using a NSAID as an adjunct in perioperative analgesia, the magnitude of the reduction in opioid consumption $(25 \mu \mathrm{g})$ and the small improvement in resting pain $(\sim 10 \mathrm{~mm}$ on a100-mm VAS) over the short duration (two hours) leaves the question whether it is clinically relevant to administer ketorolac 30 
Fig. 2 Kaplan-Meier survival curve of time to first rescue analgesic request in the postanesthesia care unit. The yaxis represents the proportion of patients without rescue analgesic at a given time ( $\mathrm{x}-$ axis) from completion of the intraperitoneal/intravenous injection until 180 min after treatment

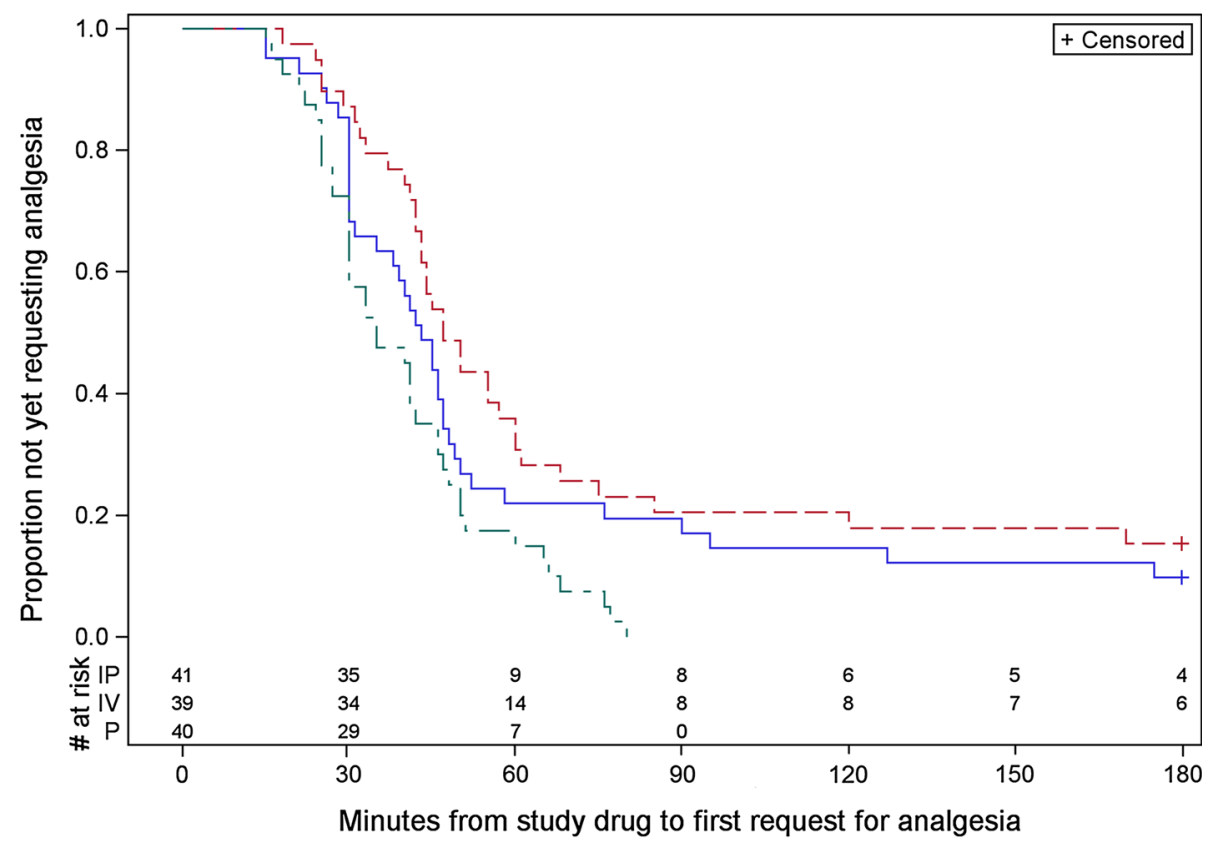

Group $\longrightarrow$ IP --- IV $---P$

Table 2 Pain, postoperative nausea and vomiting while in PACU

\begin{tabular}{llll}
\hline & $\begin{array}{l}\text { IP } \\
(n=41)\end{array}$ & $\begin{array}{l}\text { IV } \\
(n=39)\end{array}$ & $\begin{array}{l}\text { C } \\
(n=40)\end{array}$ \\
\hline $\begin{array}{l}\text { Fentanyl }(\mu \mathrm{g}), \\
\text { Mean (SD) (range) }\end{array}$ & $80(64)(0-250)^{*}$ & $67(56)(0-200)^{*}$ & $112(63)(0-250)$ \\
Nausea & $27(66)$ & $23(59)$ & $24(60)$ \\
Vomiting & $5(12)$ & $5(13)$ & $9(23)$ \\
Antiemetic & $22(54)$ & $17(44)$ & $24(60)$ \\
Shoulder pain & $3(7)^{*}$ & $4(10)^{*}$ & $12(30)$ \\
\hline
\end{tabular}

Reported as $n(\%)$ unless stated otherwise. Rescue analgesia dose, nausea and vomiting in the PACU: $* P<0.05$ vs Controls. IP $=$ intraperitoneal; IV = intravenous; $\mathrm{C}=$ controls; $\mathrm{PACU}=$ postanesthesia care unit

$\mathrm{mg}$ intraoperatively in this patient population. Also, the fact that no additional benefit was observed with intraperitoneal administration suggests that there is no role for this "off- label" route of ketorolac administration.

It has been suggested that applying NSAIDs directly where pain relief is required might allow for sufficiently high levels of analgesic effects with a reduced risk of side effects. ${ }^{10,12,13}$ Our results do not support this hypothesis. Two previous studies examined a combination of intraoperative local anesthetic and NSAID via the intraperitoneal route. ${ }^{5,14}$ Elhakim et al. ${ }^{5}$ showed an equivalent reduction in resting pain with IP and IV tenoxicam combined with lidocaine, although the time to first analgesic request and pain with movement were reduced only in the IP group. Jabbour-Khoury et al. ${ }^{14}$ found that patients who received IP local anesthesia and IV ketoprofen were the only individuals with reduced requirements for rescue analgesia with associated reductions in nausea and vomiting. Our results suggest that IP ketorolac alone has no benefit over IV ketorolac; however, a combination with local anesthetic might have potentiated its effects.

Our study may be criticized because of the questionable clinical significance of the observed difference in analgesic consumption $(25 \mu \mathrm{g})$ and resting pain scores between the ketorolac groups and the Control group while in the PACU. Also, the lack of improved efficacy with intraperitoneal administration may be attributed to a number of factors. As we did not actually measure plasma levels, it is possible that the high vascularity of the peritoneum led to systemic absorption which precluded high local concentrations. In addition, NSAIDs act at different levels along the 
nociceptive pathway, and our results may imply an important central mechanism of ketorolac in this surgical population. ${ }^{15,16} \mathrm{~A}$ recent investigation measuring systemic ketorolac levels following periarticular infiltration during hip arthroplasty revealed that plasma levels ranged from $0.3-2.2 \mathrm{mg} \cdot \mathrm{L}^{-1}$ (a range of $30 \mathrm{~min}-4 \mathrm{hr}$ to maximal plasma
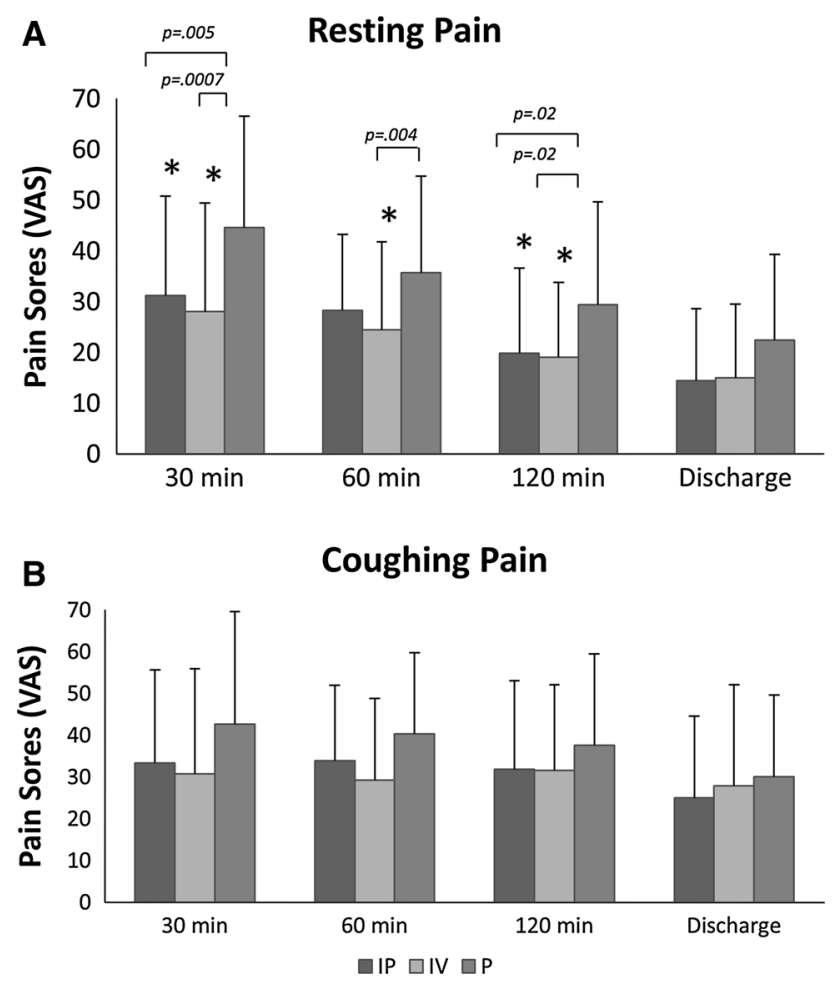

Fig. 3 Visual analogue scale (VAS) scores reported in the postanesthesia care unit at rest (A) and with coughing (B) for the three treatment groups. Bars represent means and whiskers are extended one standard deviation concentration), ${ }^{17}$ with ketorolac $30 \mathrm{mg}$ in $250 \mathrm{~mL}$ volume infiltration (similar to the concentration used here). In contrast, IV ketorolac $30 \mathrm{mg}$ peaks within 2.9 (1.8) $\mathrm{min}$ to a maximum of $4.65(0.96) \mathrm{mg} \cdot \mathrm{L}^{-1} \cdot{ }^{18}$ Even so, to our knowledge, NSAID levels at the application site following IV vs IP administration have not been measured. Direct correlations between local $v s$ plasma ketorolac levels and analgesic efficacy might provide important information regarding mode of action.

Concerns raised during the study design regarding putative effects of ketorolac on platelet aggregation led to ketorolac administration after gall bladder hemostasis was achieved. This may have introduced another limitation, however, since preemptive analgesia with peritoneal instillation of bupivacaine has been shown to provide superior analgesia. ${ }^{19}$ It also appears that the analgesic benefits of NSAIDs can be optimized by continuous prophylactic administration. ${ }^{20-22}$ Therefore, our patients may have experienced additional benefit if the ketorolac treatment had been extended and initiated preoperatively.

Another limitation of this study concerns the prolonged recruitment phase (three years), with a high exclusion rate mostly secondary to failure to meet the inclusion criteria. This limitation, together with the negative results (i.e., no advantage to intraperitoneal administration) of the study, contributed to the delay in submitting this investigation for publication. Nevertheless, this is a novel study examining the efficacy of administering intraperitoneal NSAIDs alone in this surgical population, and the findings are still relevant.

In conclusion, the efficacy of IP ketorolac was comparable to IV ketorolac in the management of immediate postoperative pain following laparoscopic

Table 3 Analgesic consumption, nausea and vomiting reported at 24-hr follow-up

\begin{tabular}{|c|c|c|c|c|}
\hline & $\begin{array}{l}\text { IP } \\
n=41\end{array}$ & $\begin{array}{l}\text { IV } \\
n=39\end{array}$ & $\begin{array}{l}\mathrm{C} \\
n=40\end{array}$ & $P$ value \\
\hline Acetaminophen (mg) & $2,147(1,340)$ & $2,103(1,597)$ & $2,409(1,173)$ & 0.40 \\
\hline Oxycodone (mg) & $8.1(10.3)$ & $13.9(14.5)$ & $12.7(11.3)$ & 0.10 \\
\hline ADL (VRS) & $5[3-6]$ & $4[2-5]$ & $4[3-5]$ & 0.41 \\
\hline \multicolumn{5}{|l|}{ Nausea } \\
\hline Unknown & $5(12)$ & $8(21)$ & $11(28)$ & \multirow[t]{3}{*}{0.38} \\
\hline Yes & $16(39)$ & $12(31)$ & $12(30)$ & \\
\hline No & $20(49)$ & 19 (49) & $17(44)$ & \\
\hline \multicolumn{5}{|l|}{ Vomiting } \\
\hline Unknown & $5(12)$ & $8(21)$ & $11(28)$ & \multirow[t]{3}{*}{0.36} \\
\hline Yes & $6(15)$ & $9(23)$ & $5(13)$ & \\
\hline No & $30(73)$ & $21(54)$ & $24(60)$ & \\
\hline
\end{tabular}

24-hr acetaminophen and oxycodone doses are expressed as mean (SD). Activities of daily living (ADL) are expressed as median verbal rating scale (VRS) scores [interquartile range]. Nausea and vomiting are expressed as $n(\%)$. IP $=$ intraperitoneal; IV $=$ intravenous; $\mathrm{C}=\mathrm{control}$ 
cholecystectomy, and both produced statistically significant reductions in opioid consumption in the PACU. Nevertheless, the clinical relevance of this difference $(\sim 25 \mu \mathrm{g})$ and the very small decrease in resting pain scores observed with both IP and IV ketorolac compared with Control is likely insignificant. Moreover, since no additional benefit was observed with intraperitoneal compared with intravenous administration, the study does not support off-label intraoperative administration of IP ketorolac for the treatment of postoperative pain in cholecystectomy patients. Further investigations powered to detect adverse effects resulting from ketorolac and opioid analgesics would be required to assess the safety impact of different routes of administration.

Author contributions: John Murdoch was involved in study conception. John Murdoch and Gillian Ramsey were involved in study design. John Murdoch, Gillian Ramsey, and Elizabeth Orr were involved in data analysis and data interpretation. John Murdoch, Michael McMullen, and Rachel Phelan were involved in drafting the manuscript. John Murdoch, Andrew G. Day, Michael McMullen, Rachel Phelan, and Diederick Jalink participated in the manuscript review process. Gillian Ramsey and Elizabeth Orr recruited patients and collected data. Andrew G. Day conducted the statistical analyses. Diederick Jalink performed the laparoscopic cholecystectomies. All the authors made significant intellectual contributions to this work.

Conflicts of interest None of the authors have any conflict of interest associated with publication of this manuscript.

Funding Funding was provided by a Queen's University Faculty of Health Sciences Research Initiation Grant and by the Queen's University Department of Anesthesiology \& Perioperative Medicine.

\section{References}

1. Bisgaard T, Klarskov B, Rosenberg J, Kehlet H. Characteristics and prediction of early pain after laparoscopic cholecystectomy. Pain 2001; 90: 261-9.

2. Joris $J$, Thiry E, Paris $P$, Weerts $J$, Lamy $M$. Pain after laparoscopic cholecystectomy: characteristics and effect of intraperitoneal bupivacaine. Anesth Analg 1995; 81: 379-84.

3. Alexander JI. Pain after laparoscopy. Br J Anaesth 1997; 79: 36978.

4. Bisgaard T. Analgesic treatment after laparoscopic cholecystectomy: a critical assessment of the evidence. Anesthesiology 2006; 104: 835-46.

5. Elhakim M, Amine H, Kamel S, Saad F. Effects of intraperitoneal lidocaine combined with intravenous or intraperitoneal tenoxicam on pain relief and bowel recovery after laparoscopic cholecystectomy. Acta Anaesthesiol Scand 2000; 44: 929-33.

6. DeAndrade JR, Maslanka M, Maneatis T, Bynum L, Burchmore $M$. The use of ketorolac in the management of postoperative pain. Orthopedics 1994; 17: 157-66.
7. Baley $K$, Michalov $K$, Kossick MA, McDowell M. Intravenous acetaminophen and intravenous ketorolac for management of pediatric surgical pain: a literature review. AANA J 2014; 82: 5364.

8. Balmaceda CM. Evolving guidelines in the use of topical nonsteroidal anti-inflammatory drugs in the treatment of osteoarthritis. BMC Musculoskelet Disord 2014; 15: 27-36.

9. O'Hara DA, Fragen RJ, Kinzer M, Pemberton D. Ketorolac tromethamine as compared with morphine sulfate for treatment of postoperative pain. Clin Pharmacol Ther 1987; 41: 556-61.

10. McCleane $G$. Topical application of analgesics: a clinical option in day case anesthesia? Curr Opin Anesthesiol 2010; 23: 704-7.

11. Ben-David B, Katz E, Gaitini L, Goldik Z. Comparison of i.m. and local infiltration of ketorolac with and without local anaesthetic. Br J Anaesth 1995; 75: 409-12.

12. Romsing $J$, Mysager $S$, Vilmann $P$, Sonne $J$, Larsen $N E$, Ostergaard $D$. Postoperative analgesia is not different after local vs systemic administration of meloxicam in patients undergoing inguinal hernia repair. Can J Anesth 2001; 48: 97884.

13. Mulshine JL, Atkinson JC, Greer RO, et al. Randomized, doubleblind, placebo-controlled phase IIb trial of cyclooxygenase inhibitor ketorolac as an oral rinse in oropharyngeal leukoplakia. Clin Canc Res 2004; 10: 1565-73.

14. Jabbour-Khoury SI, Dabbous AS, Gerges FJ, Azar MS, Ayoub $C M$, Khoury GS. Intraperitoneal and intravenous routes for pain relief in laparoscopic cholecystectomy. JSLS 2005; 9: 316-21.

15. Burian M, Tegeder I, Seegel M, Geisslinger G. Peripheral and central antihyperalgesic effects of diclofenac in a model of human inflammatory pain. Clin Pharmacol Ther 2003; 74: 11320.

16. Cashman JN. The mechanisms of action of NSAIDs in analgesia. Drugs 1996; 52(Suppl 5): 13-23.

17. Affas F, Eksborg S, Wretenberg P, Olofsson C, Stephanson N, Stiller CO. Plasma concentration of ketorolac after local infiltration analgesia in hip arthroplasty. Acta Anaesthesiol Scand 2014; 58: 1140-5.

18. Roche Pharmaceuticals. Toradol. Reference ID: 3281582, $1997-$ 2013. Available from URL: http://www.accessdata.fda.gov/ drugsatfda_docs/label/2013/019645s019lbl.pdf (accessed January 2016)

19. Barczynski M, Konturek A, Herman RM. Superiority of preemptive analgesia with intraperitoneal instillation of bupivacaine before rather than after the creation of pneumoperitoneum for laparoscopic cholecystectomy: a randomized, double-blind, placebo-controlled study. Surg Endosc 2006; 20: 1088-93.

20. Wilson YG, Rhodes M, Ahmed R, Daugherty M, Cawthorn SJ, Armstrong $C P$. Intramuscular diclofenac sodium for postoperative analgesia after laparoscopic cholecystectomy: a randomised, controlled trial. Surg Laparosc Endosc 1994; 4: 3404.

21. Gan TJ, Joshi GP, Viscusi E, et al. Preoperative parenteral parecoxib and follow-up oral valdecoxib reduce length of stay and improve quality of patient recovery after laparoscopic cholecystectomy surgery. Anesth Analg 2004; 98: 1665-73.

22. Joshi GP, Viscusi ER, Gan TJ, et al. Effective treatment of laparoscopic cholecystectomy pain with intravenous followed by oral COX-2 specific inhibitor. Anesth Analg 2004; 98: 336-42. 